\title{
Kinetic Analysis of the Gasification of Diamond
}

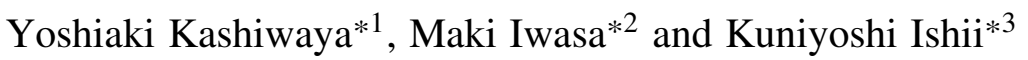 \\ Graduate School of Engineering, Hokkaido University, Sapporo 060-8628, Japan
}

\begin{abstract}
Diamond is the ultimate state of carbon crystal. However, a transformation from diamond to graphite during gasification occurs under oxidizing atmosphere. The gasification behaviors of diamond vary with the reaction gas composition and temperature.

There has been no kinetic study on the diamond gasification. Most of the interest in this area has been related to diamond growth.

The change of morphology of diamond surface and the crystallographic orientation between the diamond and the graphite formed was presented in a previous study.

In this study, the gasification of natural diamond was investigated using TG-DTA. Kinetic analysis was performed on the basis of Langmuir-Hinshelwood type equation, in which some rate constant was modified from the previous study for coke gasification. SEM observations of the diamond surface were carried out in order to clarify the change in surface morphology. Moreover, the simultaneous gasification of diamond and graphite was carried out in order to clarify the difference in reactivity between ordinary graphite and graphite formed on the diamond during gasification. [doi:10.2320/matertrans.MRA2008069]
\end{abstract}

(Received March 10, 2008; Accepted April 14, 2008; Published June 25, 2008)

Keywords: gasification of diamond, kinetic analysis, transformation from diamond to graphite

\section{Introduction}

Gasification of various kinds of carbonaceous materials (graphite, char, coke and so on) has been studied for the last several decades. ${ }^{1-7)}$ Generally, Langmuir-Hinshelwood (L-H) type rate equation was adopted for the kinetic analysis, in which one kind of carbon having a single reactivity was considered. However, the reactivity of carbonaceous material decreases with the degree of graphitization. Conversely, it increases as the material transforms into non-crystalline (amorphous) carbon. The authors ${ }^{5)}$ have presented the mechanism of gasification based on the anisotropic nature of the graphite crystal. For this kinetic analysis, the reactivity of carbon was classified into two groups: one was the graphite crystal having a low reactivity, and the other was non-crystal carbon having a high reactivity.

Alternatively, diamond can be considered an ultimate state of carbon crystal. The present authors carried out the gasification of natural diamond ${ }^{8)}$ and clarified the behavior of gasification, both under a low oxygen partial pressure in an $\operatorname{argon}(<20 \mathrm{ppm})$ and under an argon- $\mathrm{CO}_{2}$ mixture, specifically $\mathrm{Ar}-30 \mathrm{vol} \% \mathrm{CO}_{2}$. The gasification behaviors of diamond were different from the reaction gas composition; however, the transformation from diamond to graphite during gasification was the same. The crystallographic orientation between the diamond and the formed graphite was presented in the previous study. ${ }^{8)}$

As mentioned above, there have been many studies on the gasification of various kinds of carbon. However, no gasification study has been conducted for the diamond. Most of the interest seen thus far has been related to diamond growth. The purpose of this series of studies is to investigate the diamond behavior occurring in a direction opposite to that of growth.

\footnotetext{
${ }^{* 1}$ Corresponding author, E-mail: yoshiaki@eng.hokudai.ac.jp

${ }^{*}$ Graduate Student, Hokkaido University, Present address: JFE Steel, Co. Ltd.

${ }^{*}$ Emeritus Professor, Hokkaido University, Present address: JFE Steel, Co. Ltd.
}

In this study, the gasification reaction of a small diamond particle $(2 \mathrm{mg} \pm 0.1 \mathrm{mg}$ ) was carried out, mainly under Ar$30 \mathrm{vol} \% \mathrm{CO}_{2}$, the effects of gas composition and temperature were also clarified in comparison with the graphite gasification.

\section{Experimental}

\subsection{Apparatus and conditions}

Figure 1 shows the experimental apparatus including the TG-DTA equipment, gas controller (MFC: mass flow controller) and a gas analyzing device (QMS: quadrupole mass spectrometer). In the present experiment, a horizontal type TG-DTA, and a platinum crucible $(5 \mathrm{~mm} \phi$ and $2.5 \mathrm{~mm}$ in depth) were used. The minimum mass sensitivity of TG is $0.2 \mu \mathrm{g}$.

The diamond sample was heated up to the reaction temperature (Table 1) at a rate of $50 \mathrm{~K} / \mathrm{min}$ under an argon atmosphere. The reaction gas was adjusted in the by-pass using MFC. The total flow rate of the reaction gas was $500 \mathrm{Ncc} / \mathrm{min}$ (linear velocity: $3 \mathrm{~cm} / \mathrm{s}$ ), and the main gas

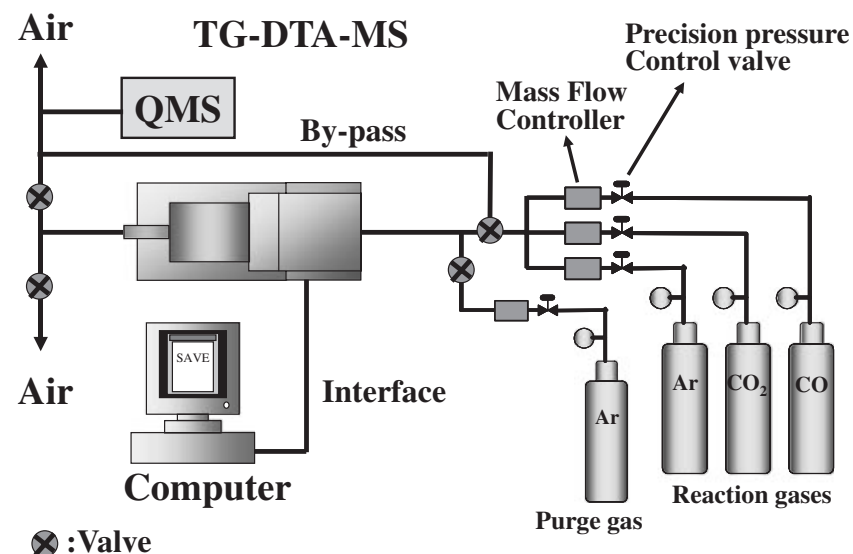

Fig. 1 Schematics of experimental apparatus consisted of TG-DTA-MS system and gas controlling system. 
Table 1 Experimental conditions.

\begin{tabular}{|c|c|c|c|c|}
\hline \multirow{2}{*}{ Notation } & \multirow{2}{*}{ Sample (s) } & Total flow rate: $500 \mathrm{Ncc} / \mathrm{min}$ & \multirow{2}{*}{ Reaction Temp. } & \multirow{2}{*}{ Reaction Time } \\
\hline & & Gas composition & & \\
\hline Exp-0 & $\begin{array}{l}\text { Graphite } \\
(\text { ash < } 100 \mathrm{ppm})\end{array}$ & 30 vol $\% \mathrm{CO}_{2}-\mathrm{Ar}$ & $1473 \mathrm{~K}$ & $1800 \mathrm{~s}$ \\
\hline Exp-1 & Diamond (natural) & $30 \mathrm{vol} \% \mathrm{CO}_{2}-\mathrm{Ar}$ & $1473 \mathrm{~K}$ & $1800 \mathrm{~s}$ \\
\hline Exp-2 & Diamond (natural) & $\begin{array}{l}20,30,40,60 \\
80 \text { vol } \% \mathrm{CO}_{2}-\mathrm{Ar}\end{array}$ & $1473 \mathrm{~K}$ & $1800 \mathrm{~s}$ \\
\hline Exp-3 & Diamond (natural) & $\begin{array}{l}5 \text { vol } \% \mathrm{CO}-30 \text { vol } \% \mathrm{CO}_{2}-\mathrm{Ar} \\
10 \mathrm{vol} \% \mathrm{CO}-30 \text { vol } \% \mathrm{CO}_{2}-\mathrm{Ar}\end{array}$ & $1473 \mathrm{~K}$ & $1800 \mathrm{~s}$ \\
\hline Exp-4 & Diamond (natural) & $30 \mathrm{vol} \% \mathrm{CO}_{2}-\mathrm{Ar}$ & $\begin{array}{l}1273 \mathrm{~K}, 1373 \mathrm{~K}, \\
1473 \mathrm{~K}, 1573 \mathrm{~K}\end{array}$ & $1800 \mathrm{~s}$ \\
\hline Exp-5 & Diamond (natural) & $30 \mathrm{vol} \% \mathrm{CO}_{2}-\mathrm{Ar}$ & $1473 \mathrm{~K}$ & $5400 \mathrm{~s}$ \\
\hline Exp-6 & $\begin{array}{l}\text { Diamond \& } \\
\text { Graphite }\end{array}$ & $30 \mathrm{vol} \% \mathrm{CO}_{2}-\mathrm{Ar}$ & $1473 \mathrm{~K}$ & $1800 \mathrm{~s}$ \\
\hline
\end{tabular}

composition was $\mathrm{Ar}-30 \mathrm{vol} \% \mathrm{CO}_{2}$. As the TG-DTA is of the horizontal type (SII, TG/DTA5200), a relatively high flow rate can be used until $1000 \mathrm{Ncc} / \mathrm{min}$. It was confirmed that the gas phase mass transport was negligible from $500 \mathrm{Ncc} /$ $\min$ for the highest gasification rate of the graphite sample (EXP-0).

The basic reaction in the present study can be expressed by eq. (1).

$$
\mathrm{C} \text { (diamond, graphite })+\mathrm{CO}_{2}(\mathrm{~g})=2 \mathrm{CO}(\mathrm{g})
$$

It is understood from eq. (1) that the effect of the produced $\mathrm{CO}$ gas on the inhibition of the gasification reaction is important. The range of $\mathrm{CO}_{2}$ composition of the reaction gas was changed from 20 vol\% to 80 vol\% (Exp-2), and the CO composition was changed from $0 \mathrm{vol} \%$ to $10 \mathrm{vol} \%$ (Exp-3). In addition, the effect of the temperature on the gasification reaction of diamond was also examined from $1273 \mathrm{~K}$ to $1573 \mathrm{~K}$ (Exp-4).

When the reaction temperature became stable, the reaction gas in the by-pass was introduced to the TG-DTA, and the reaction started. The mass loss of diamond was continuously measured in $1 \mathrm{~s}$ intervals and corrected on the computer. The reaction time was set at $1800 \mathrm{~s}$ (30 $\mathrm{min})$ as a main condition, and the effect of the experiment time was examined in an experiment with $5400 \mathrm{~s}(90 \mathrm{~min}$; Exp-5). It is important to note that the effect of the experiment time might be related to the change of the reaction mechanism according to the decrease of the diamond sample.

Finally, the simultaneous reactions between graphite and diamond were investigated and the effect of the produced gas (CO) on the neighbor sample was studied (Exp-6). This experiment also examined the difference in reactivity between the conventional graphite sample and the sample formed on the diamond surface during the gasification process.

\subsection{Sample served}

The mass of the diamond used in the present study was about $2 \mathrm{mg}( \pm 0.1 \mathrm{mg})$. The diamond was not spherical in shape. The surface of the natural diamond consisted of $\{111\}$ as the habit plane; ${ }^{8)}$ the length of an edge of the equilateral triangle was about $750 \mu \mathrm{m}$. Figure 2 shows the morphology of the diamond samples used before and after the experiment. Figures 2(a)-(c) show the image of same sample, using a different observation method, and the difference before and after the experiment. Figure 2(a) is the image of optical microscope and Fig. 2(b) shows the image obtained by the laser microscope, which gives detailed information about the sample surface. With the laser microscope, it was found that the roughness of the diamond surface was intensified and the difference in the distance from an observation point can be emphasized at the edge of the plane. Figure 2(c) shows the image from the optical microscope after the experiment at $1773 \mathrm{~K}$ under an argon atmosphere $\left(\mathrm{P}_{\mathrm{O} 2}<20 \mathrm{ppm}\right)$. The slightly oxidized surface, which was confirmed as a kind of graphite layer, ${ }^{8)}$ can be observed. Figure 2(d) shows the diamond image after the experiment at $1473 \mathrm{~K}$ under Ar$30 \mathrm{vol} \% \mathrm{CO}_{2}$ for $1800 \mathrm{~s}$. The gasification degree seen in Fig. 2(d) is $5.5 \%$, and a relatively thick layer of product, which was also confirmed as the same structure with graphite, was formed on the surface of the diamond. However, the reactivity between the ordinary graphite and the graphite-like product that formed on the diamond surface was fairly different. The details will be mentioned in a later section of the present paper.

\section{Results and Discussion}

\subsection{Typical gasification behavior of diamond and graph- ite, and kinetic analysis}

The typical reaction curves for the diamond (Exp-0) and graphite (Exp-1) are shown in Fig. 3. The temperature increased from room temperature to a given temperature ( $1473 \mathrm{~K}$ in the case of Fig. 3) at a rate of $50 \mathrm{~K} / \mathrm{min}$ under ultra high purity (>99.9999\%) Ar. When the temperature was stabilized, the argon gas was changed to the reaction gas. The weight loss of sample was measured for $1800 \mathrm{~s}(30 \mathrm{~min})$ at the reaction temperature, then, the reaction gas was changed again to $\mathrm{Ar}$ and the temperature was decreased by turning off the power to the TG-DTA electric furnace.

During heating up under argon, the weight loss of samples was negligible. The gasification reaction of both samples 

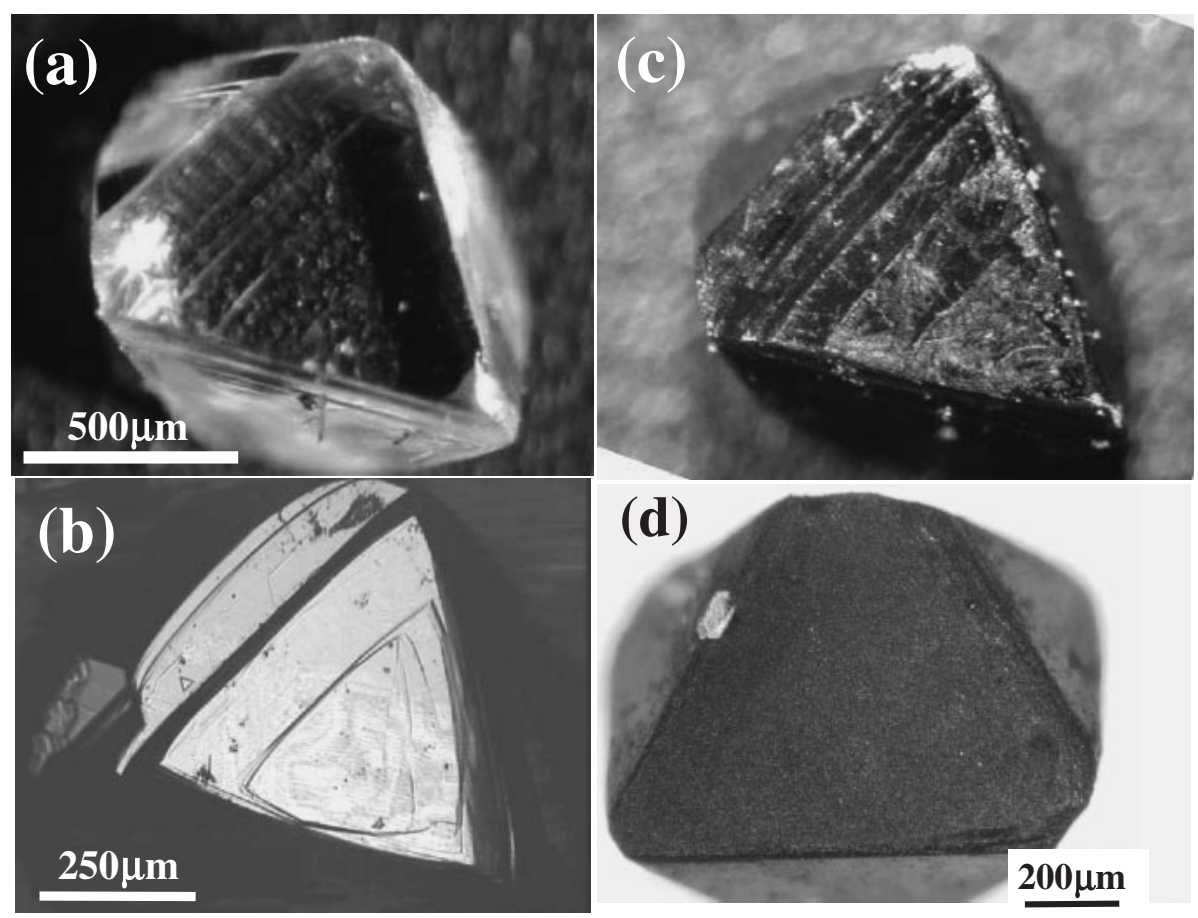

Fig. 2 Appearances of diamond surface before and after experiments. (a) before exp. by optical microscope, (b) before exp. by laser microscope, (c) after exp. by optical microscope (max temp.: $1773 \mathrm{~K}$ under argon), (d) after exp. at $1473 \mathrm{~K}$ under $\mathrm{Ar}-30 \% \mathrm{CO}_{2}$ for $1800 \mathrm{~s}$.

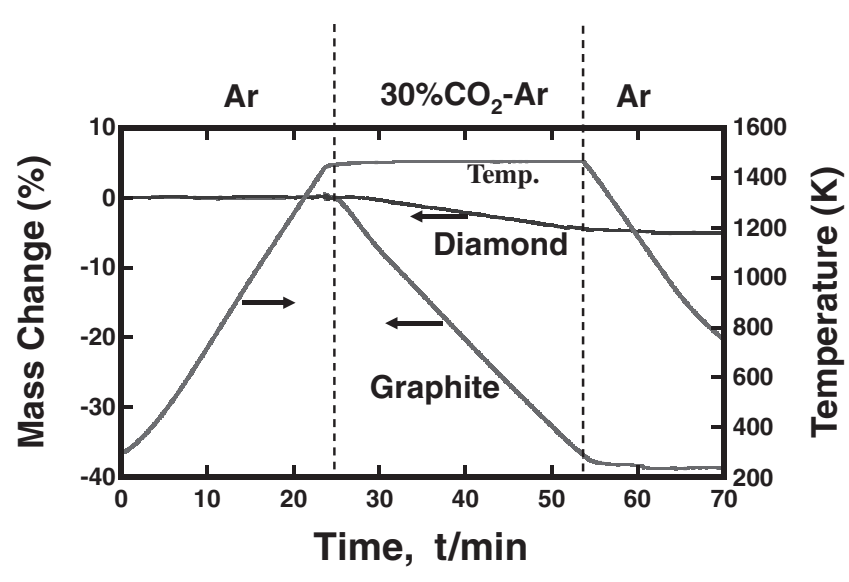

Fig. 3 Difference of mass change between diamond and graphite obtained by TG-DTA during gasification. (Heating up rate: $50 \mathrm{~K} / \mathrm{min}$, reaction temp.: $1473 \mathrm{~K}, \mathrm{Ar}-30$ vol\% $\mathrm{CO}_{2}$, Flow rate: $500 \mathrm{Ncc} / \mathrm{min}$ ).

began as soon as the reaction gas was introduced. It was found that the rate of weight loss (gasification rate: slope of the line) was linear to the reaction time. Within a $30 \mathrm{~min}$ reaction time, the degree of gasification of diamond was about $5 \%$, and that for graphite was $38 \%$. The rate of gasification of graphite was 7.5 times larger than that of diamond.

For the kinetic analysis, two kinds of equations were examined for agreement with the experimental data. The rate equations are summarized in Table 2, where $\dot{r}\left(\mathrm{~s}^{-1}\right)$ is reaction rate, $x(-)$ means the fraction of unreacted carbon, $t$ (s) is the time, $A\left(\mathrm{~cm}^{2}\right)$ is the surface area of the sample, and $k\left(\mathrm{~s}^{-1} \mathrm{~cm}^{-2}\right)$ is the overall rate constant, which is expressed by a Langmuir-Hinshelwood type equation (details are mentioned below). As the exact surface area of sample is not known, $A$ and $k$ are unified into $k^{\prime}$. Equation (2) describes
Table 2 Rate equations examined in the present study.

\begin{tabular}{lll}
\hline$\dot{r}=\frac{d x}{d t}=-A k=-k^{\prime}$ & (2) & $\dot{r}=\frac{d x}{d t}=-A k x=-k^{\prime} x$ \\
\hline$d x=-A k d t$ & (3) & $\frac{d x}{x}=-A k \cdot d t$ \\
\hline $\begin{array}{c}x=-A k t+C \\
\text { at } t=0, x=1, C=1\end{array}$ & (4) & $\begin{array}{c}\ln x=-A k t+C \\
\text { at } t=0, x=1, C=1\end{array}$ \\
\hline$x-1=-A k t$ & (5) & $\ln x=-A k t$ \\
\hline
\end{tabular}

the surface reaction of a sample with linearity to time. Equation (6) describes the homogeneous reaction in the sample, which is generally adaptable to a porous sample such as a char, coke or graphite. The plots $(1-x) v$ s. $t$ or $\ln (x) v s$. $t$ indicate an adequate rate equation for the present experiment.

Kashiwaya et al. have performed kinetic analysis on the coke gasification reaction. ${ }^{4)}$ In the kinetic analysis, they adopted the Langmuir-Hinshelwood type (L-H) equation and the reactivity of carbon was classified into two types: one is a crystallized carbon (graphite crystal) which has a low reactivity: the other is non-crystal carbon (amorphous carbon), which has a high reactivity. Equation (10) corresponds to the rate constant of crystallized carbon (graphite), $k_{C}$ and eq. (11) corresponds to the non-crystal carbon (amorphous), $k_{a}$. These rate constants are expressed by eqs. (12)-(15).

In the present study, based on the graphite rate constant, eq. (10), the rate constant for diamond and graphite (electrode material with low ash) was expressed as eq. (16), in which a factor for the rate constant, $F_{d}$ was introduced. Furthermore, reaction constants $\left(k_{1, d}\left(\mathrm{~s}^{-1} \mathrm{~atm}^{-1}\right), k_{2, d}\left(\mathrm{~atm}^{-1}\right)\right.$, $k_{3, d}\left(\mathrm{~atm}^{-1}\right)$ ) were adjusted for fitting the experimental data based on the rate parameters of graphite, eqs. (12), (14) and 


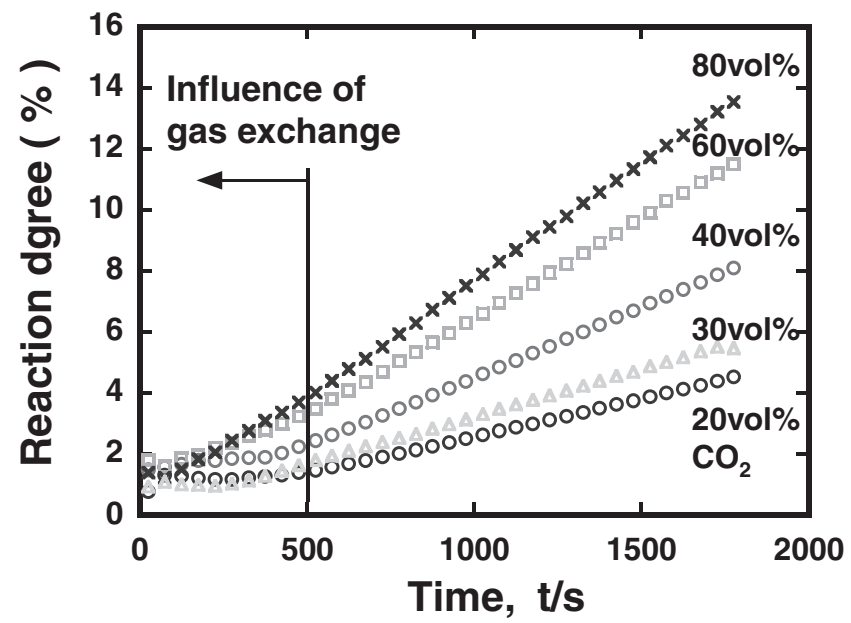

Fig. 4 Effect of $\mathrm{CO}_{2}$ on the gasification of diamond (Exp-2).

(15). The obtained parameters are shown in eqs. (17) to (20). It was found that the activation energies were the same as for graphite and pre-exponential factors were changed a little. Coke gasification ${ }^{4)}$ :

$$
\begin{aligned}
& k_{C}=\frac{k_{1, C} P_{\mathrm{CO}_{2}}}{1+k_{2} P_{\mathrm{CO}}+k_{3} P_{\mathrm{CO}_{2}}} \\
& k_{a}=\frac{k_{1, a} P_{\mathrm{CO}_{2}}}{1+k_{2} P_{\mathrm{CO}}+k_{3} P_{\mathrm{CO}_{2}}} \\
& k_{1, C}=\exp (9.49-24200 / T) \\
& k_{1, a}=\exp (4.19-13400 / T) \\
& k_{2}=\exp (-17.7+27700 / T) \\
& k_{3}=\exp (-1.59+5680 / T)
\end{aligned}
$$

Diamond and graphite gasification in present study:

$$
\begin{aligned}
& k^{\prime}=\frac{F_{\mathrm{d}} k_{1, \mathrm{~d}} P_{\mathrm{CO}_{2}}}{1+k_{2, \mathrm{~d}} P_{\mathrm{CO}}+k_{3, \mathrm{~d}} P_{\mathrm{CO}_{2}}} \\
& F_{\mathrm{d}}=0.116 \text { (diamond) }, \\
& F_{\mathrm{d}}=0.8 \text { (graphite) } \\
& k_{1, \mathrm{~d}}=\exp (9.49-24200 / T) \\
& k_{2, \mathrm{~d}}=\exp (-15.8+27700 / T) \\
& k_{3, \mathrm{~d}}=\exp (-5.53+5680 / T)
\end{aligned}
$$

\subsection{Effects of $\mathrm{CO}_{2}$ and $\mathrm{CO}$ gases and temperature on the gasification of diamond}

The effect of $\mathrm{CO}_{2}$ on the gasification of diamond was examined under the conditions of "Exp-2" listed in Table 1. The results of Exp-2 are shown in Fig. 4. The gasification reaction began $500 \mathrm{~s}$ after the reaction gas was changed to the furnace, which was an influence of gas exchange with the purging Ar. After $500 \mathrm{~s}$, the apparent reaction degree $\left(=\frac{\Delta W}{W_{O}} \times 100,1-x=\frac{W}{W_{O}}\right.$, where $W_{O}$ is the initial weight and $\Delta W$ is the change of weight by the reaction) increased linearly with time. After $1800 \mathrm{~s}$ of reaction, the gasification degree was about $4 \%$ for $20 \mathrm{vol} \% \mathrm{CO}_{2}$, and about $13.5 \%$ for 80 vol\% $\mathrm{CO}_{2}$.

Figure 5 shows the effect of $\mathrm{CO}$ gas on the gasification reaction (Exp-3). The composition of the reaction gases was changed to two levels: 5 vol\%CO-30 vol\% $\mathrm{CO}_{2}-\mathrm{Ar}$ and

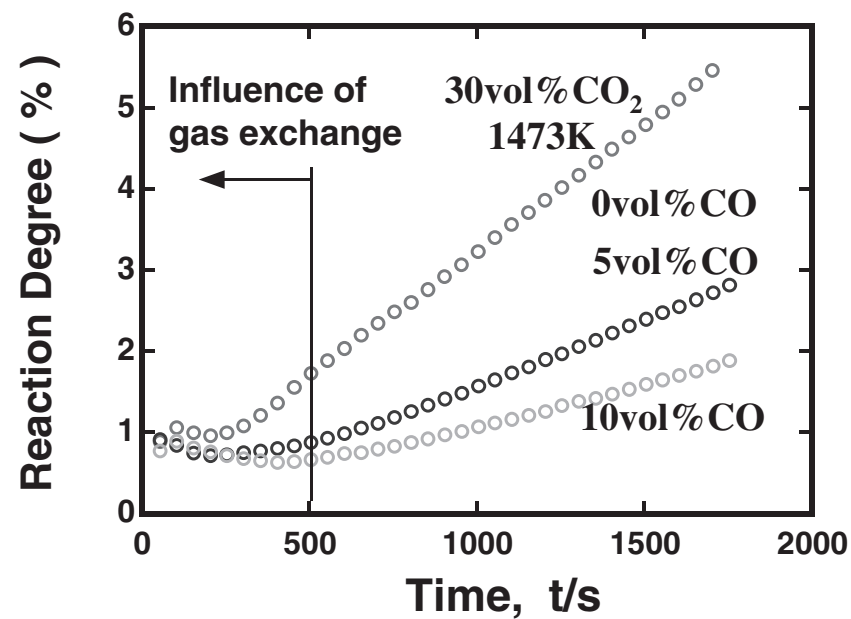

Fig. 5 Effect of $\mathrm{CO}$ on the gasification of diamond (Exp-3).

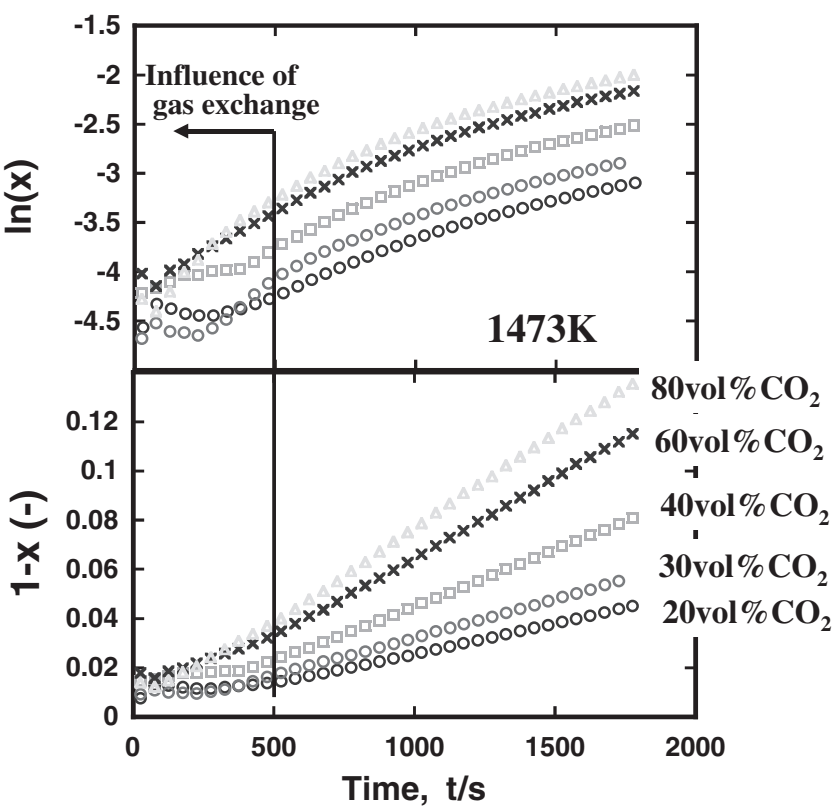

Fig. 6 Plots of $(1-x)$ v.s. $t$ and $\ln (x)$ v.s. $t$ for determining the adequate rate equation. The linearity of $(1-x)$ v.s. $t$ was higher than that of $\ln (x)$ v.s. $t$ after $500 \mathrm{~s}$.

$10 \mathrm{vol} \% \mathrm{CO}-30 \mathrm{vol} \% \mathrm{CO}_{2}-\mathrm{Ar}$. It was found that the small quantity of $\mathrm{CO}$ gas (up to $5 \mathrm{vol} \% \mathrm{CO}$ ) had a relatively large inhibition effect on the gasification reaction in comparison with the 0 vol $\% \mathrm{CO}-30$ vol $\% \mathrm{CO}_{2}$.

Using these data, kinetic analysis was carried out. At first, the adequate reaction equation was examined for determining the mechanism of diamond gasification. As mentioned above, the plots $(1-x) v s . t$ or $\ln (x) v s . t$ are shown in Figs. 6 and 7. After $500 \mathrm{~s}$, when no influence of gas exchange existed, a linear relationship of $(1-x)$ vs. $t$ was obtained for all conditions and the correlation factors of the least square method were more than 0.9995 . In the case of $\ln (x) v s$. $t$, it was difficult to detect any linearity.

Hereinafter, the plot of $(1-x) v s$. $t$ was used for kinetic analysis and the rate constants $k^{\prime}$ were measured for the slopes of the respective plots. As a result, the gasification degree and $(1-x)$ were the same. 


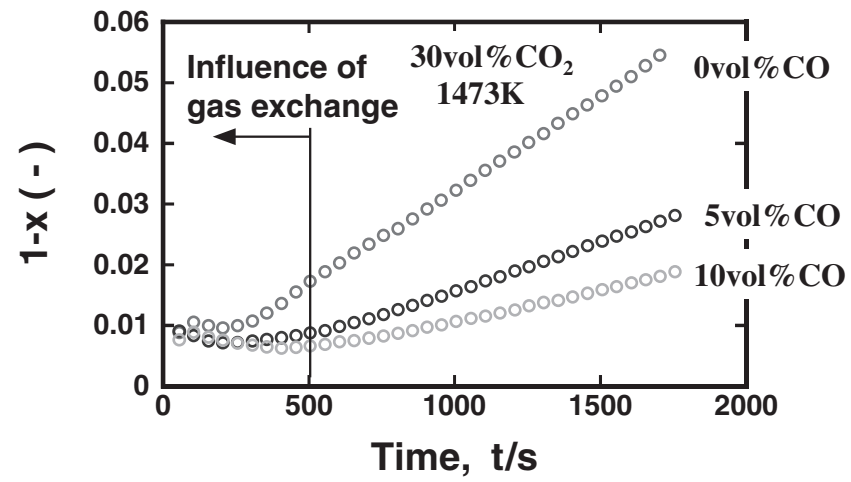

Fig. 7 Plot of $(1-x)$ v.s. $t$ for the effect of CO gas.

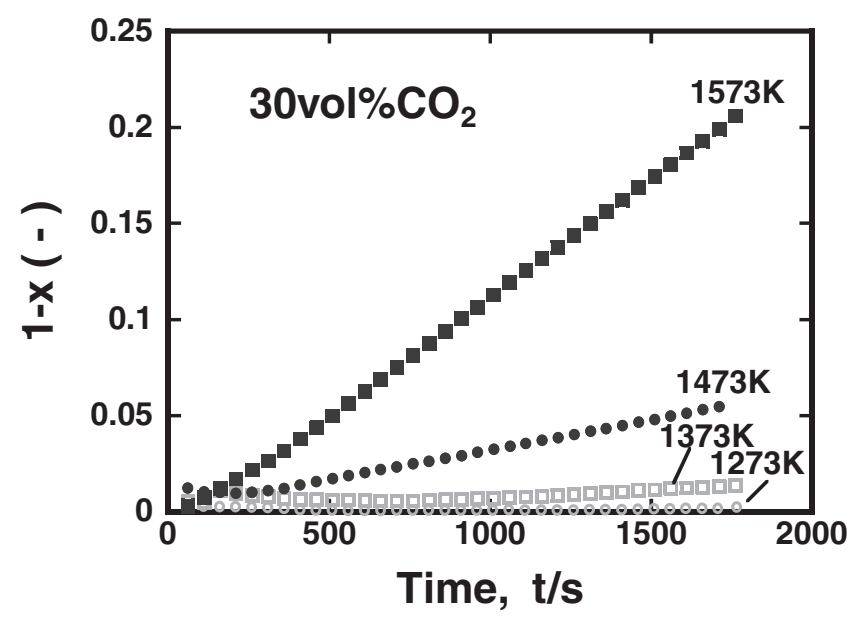

Fig. 8 Plot of $(1-x)$ v.s. $t$ for the effect of temperature.

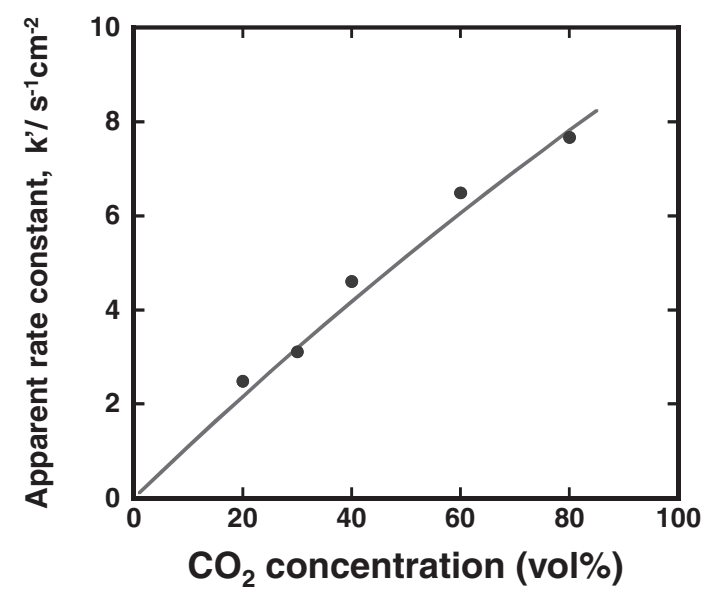

Fig. 9 Effect of $\mathrm{CO}_{2}$ on the apparent rate constants $k^{\prime}$ and calculation result.

Figure 8 shows the effect of temperature on the gasification reaction of diamond. The reaction at $1273 \mathrm{~K}$ was very small. When the temperature increased, the reaction degree increased rapidly. At $1573 \mathrm{~K}$, the gasification degree reached about $20 \%$ in $1800 \mathrm{~s}$.

From these plots, the rate constants $k^{\prime}$ were obtained and are summarized in Figs. 9 to 11. The lines in these figures were calculated using eqs. (16)-(20). Excellent agreement was obtained with experimental data for all experimental

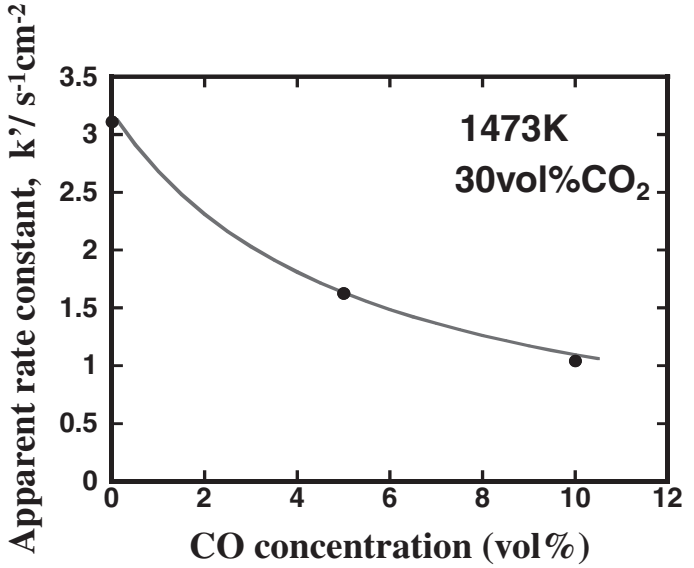

Fig. 10 Effect of $\mathrm{CO}$ on the apparent rate constants $k^{\prime}$ and calculation result.

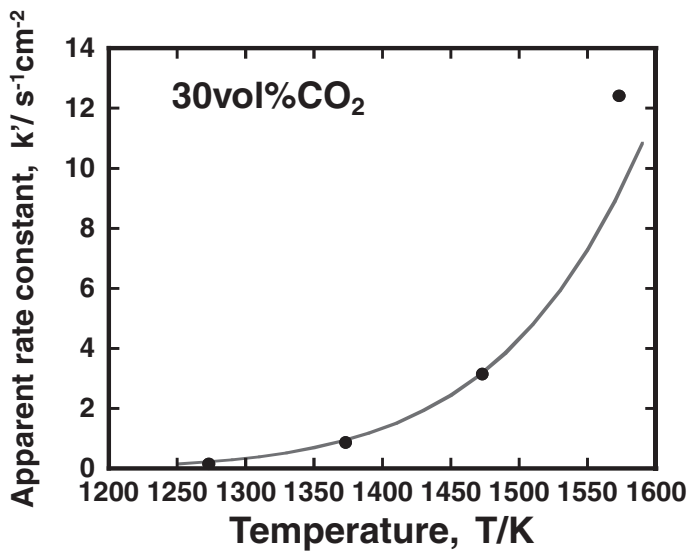

Fig. 11 Effect of temperature on the apparent rate constants $k^{\prime}$ and calculation result.

conditions. The activation energies for the reaction parameters in the $\mathrm{L}-\mathrm{H}$ equation were the same for graphite as those obtained by the previous study. ${ }^{4)}$ Only pre-exponential factors (frequency factors) were changed, which corresponded to the decrease of reaction surface or reaction sites.

\subsection{SEM observation of the surface after gasification}

Figure 12 shows observations of the diamond surface after gasification (Exp-2). The gasification reaction proceeded at the center of a defect, which has the shape of an equilateral triangle consisting of $\{111\}$ planes. In Fig. 12(a), the traces of the triangle can be seen slightly, and three cracks propagating from the pit located at the center of the triangle are clearly found in the three directions. The pits enlarged in accordance with the increase in gasification degree (Fig. 12(b), $40 \mathrm{vol} \% \mathrm{CO}_{2}$ ), and the large hole, along with the crack, which has an irregular shape, appeared in the further reaction degree (Fig. 12(c)). When the gasification potential of the reaction gas increased to $80 \mathrm{vol} \% \mathrm{CO}_{2}$, the crack and the pit became deeper but not wider. The surface roughness in the other parts of the crack decreased. The gasification proceeded at a limited reaction site in the case of low oxygen potential, and in contrast, under a relatively high oxygen potential the reaction proceeded throughout the surface. 

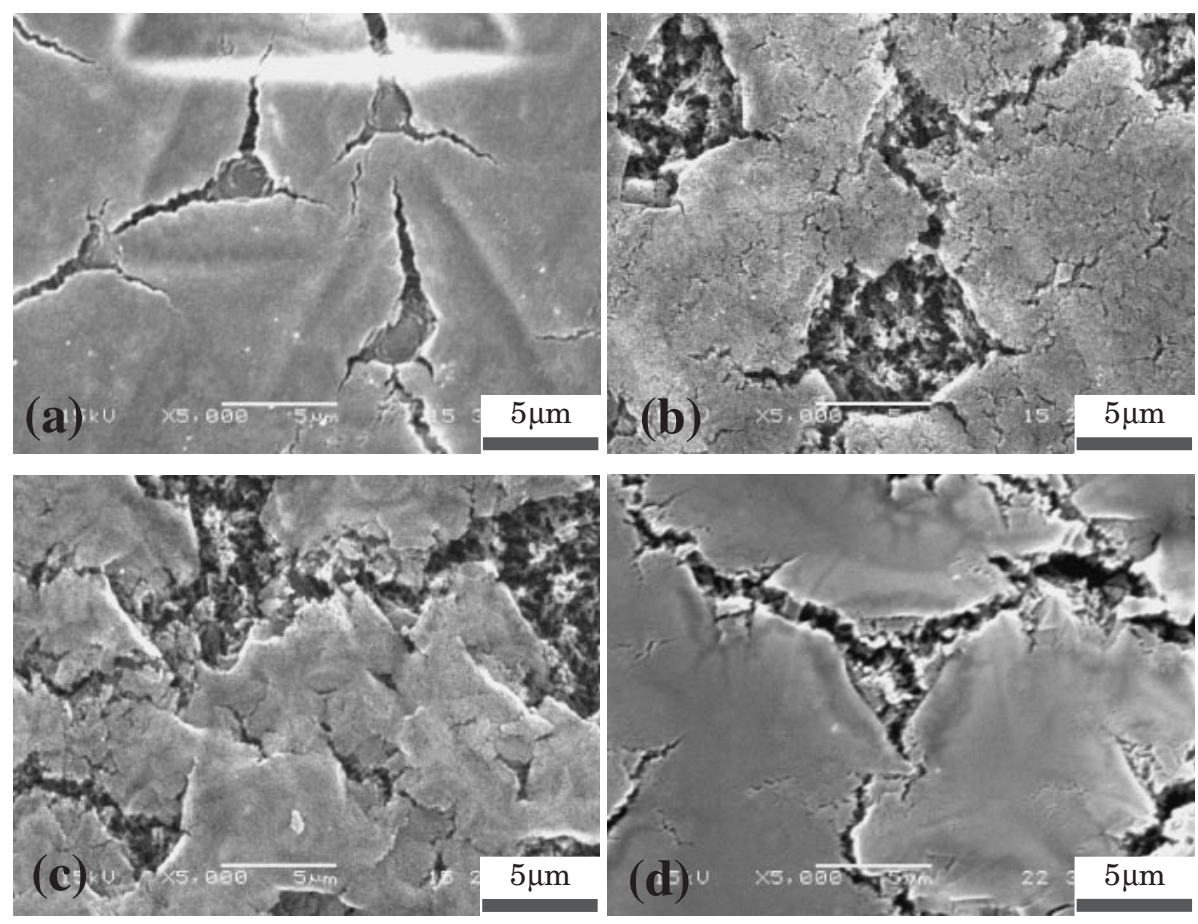

Fig. 12 Effect of $\mathrm{CO}_{2}$ concentration on the surface morphology after gasification at $1473 \mathrm{~K}$. (a) 20 vol\% $\mathrm{CO}_{2}$, reaction degree $4.5 \%$,

(b) $40 \mathrm{vol} \% \mathrm{CO}_{2}$, reaction degree $8 \%$, (c) $60 \mathrm{vol} \% \mathrm{CO}_{2}$, reaction degree $11.5 \%$, (d) $80 \mathrm{vol} \% \mathrm{CO}_{2}$, reaction degree $13.5 \%$.
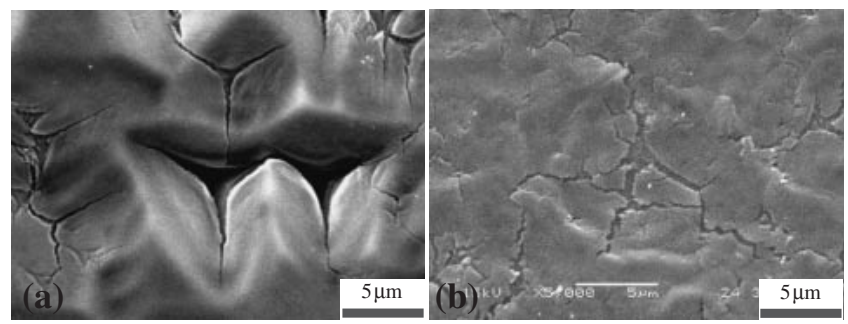

Fig. 13 Effect of $\mathrm{CO}$ concentration on the surface morphology after gasification under $30 \mathrm{vol} \% \mathrm{CO}_{2}$ at $1473 \mathrm{~K}$. (a) $5 \mathrm{vol} \% \mathrm{CO}$, reaction degree $2.8 \%$, (b) $10 \mathrm{vol} \% \mathrm{CO}$, reaction degree $1.8 \%$.

Figure 13 shows the effect of $\mathrm{CO}$ gas on the surface morphology after gasification (Exp-3). Figures 13(a) and (b) correspond to $5 \mathrm{vol} \% \mathrm{CO}$ and $10 \mathrm{vol} \% \mathrm{CO}$, respectively. Figure 13(a) shows a smooth but waved surface except the position of cracks. The position of the triangle was smoothly dimpled by the gasification reaction, and the three cracks and the pit merged into an open tripod shape. As shown in Fig. 13(b), the CO inhibition effect increased with 10 vol\%$\mathrm{CO}$, and the depth of cracks and pits became shallow, but the whole surface was coarser than the surface under 5 vol\% CO.

The effect of temperature (Exp-4) on the surface morphology after gasification is shown in Figs. 14(a) to (d), which reacted at $1273 \mathrm{~K}, 1373 \mathrm{~K}, 1473 \mathrm{~K}$ and $1573 \mathrm{~K}$, respectively, for $30 \mathrm{vol} \% \mathrm{CO}_{2}$. As shown in Fig. 8, little gasification occurred at $1273 \mathrm{~K}$ (Fig. 14(a)). Only small pits around $1 \mu \mathrm{m}$ could be observed, although the depth was not measured. When temperature increased, the surface morphology drastically changed, but the mode of change was different from reaction temperature. At $1473 \mathrm{~K}$, the surface around the triangle (cf. Fig. 12) appeared peeled, and small crack formed around the triangle. At $1573 \mathrm{~K}$, the maximum temperature, a particular crack formed more than the others, and became a very deep.

In Exp-5, the effect of experimental time on the morphology change was observed through SEM, and the results are shown in Fig. 15. The result of $1800 \mathrm{~s}(30 \mathrm{~min})$ is shown Figs. 15(a) and (c), and the result for $5400 \mathrm{~s}$ (90 $\mathrm{min}$ ) is shown in Figs. 15(b) and (d). The reaction degree was 5.5\% for $1800 \mathrm{~s}$ and $16.4 \%$ for $5400 \mathrm{~s}$. The macroscopic images are Fig. 15(a) and (b) for $1800 \mathrm{~s}$ and $5400 \mathrm{~s}$, respectively. A large triangular pit near $100 \mu \mathrm{m}$ is shown in Fig. 15(a), but small pits around 10-20 $\mu \mathrm{m}$ were found on the diamond surface for the longer experiment. Furthermore, the corner and the edge of the diamond were preferentially gasified after $5400 \mathrm{~s}$.

From these results, the fundamental mechanism of diamond surface gasification was considered, as shown in Fig. 16. As mentioned above and in reference, ${ }^{8)}$ the original diamond surface had many triangular defects consisting of $\{111\}$. When the surface was gasified, a pit formed at the center of the triangle as shown in Fig. 16(b). Then, three cracks propagated from the pit in three separate directions (Fig. 16(c)). Finally, the pit and cracks were enlarged by the gasification process (Fig. 16(d)). Although the morphology of the surface (depth and width of the cracks) was variously changed by the gasification potential, the fundamental mechanism would proceed as shown in Fig. 16.

The experimental time was extended to $5400 \mathrm{~s}$ in Exp-5 and compared with the result of the $1800 \mathrm{~s}$ of Exp- 1 . The gasification degree was $17 \%$ at $5400 \mathrm{~s}$, the linearity was very high, and the correlation factor of the least square method was more than 0.9995 . The maximum gasification degree in the present study was $20 \%$ at $1573 \mathrm{~K}$. It could be concluded that the linearity with time was valid until at least $20 \%$. 


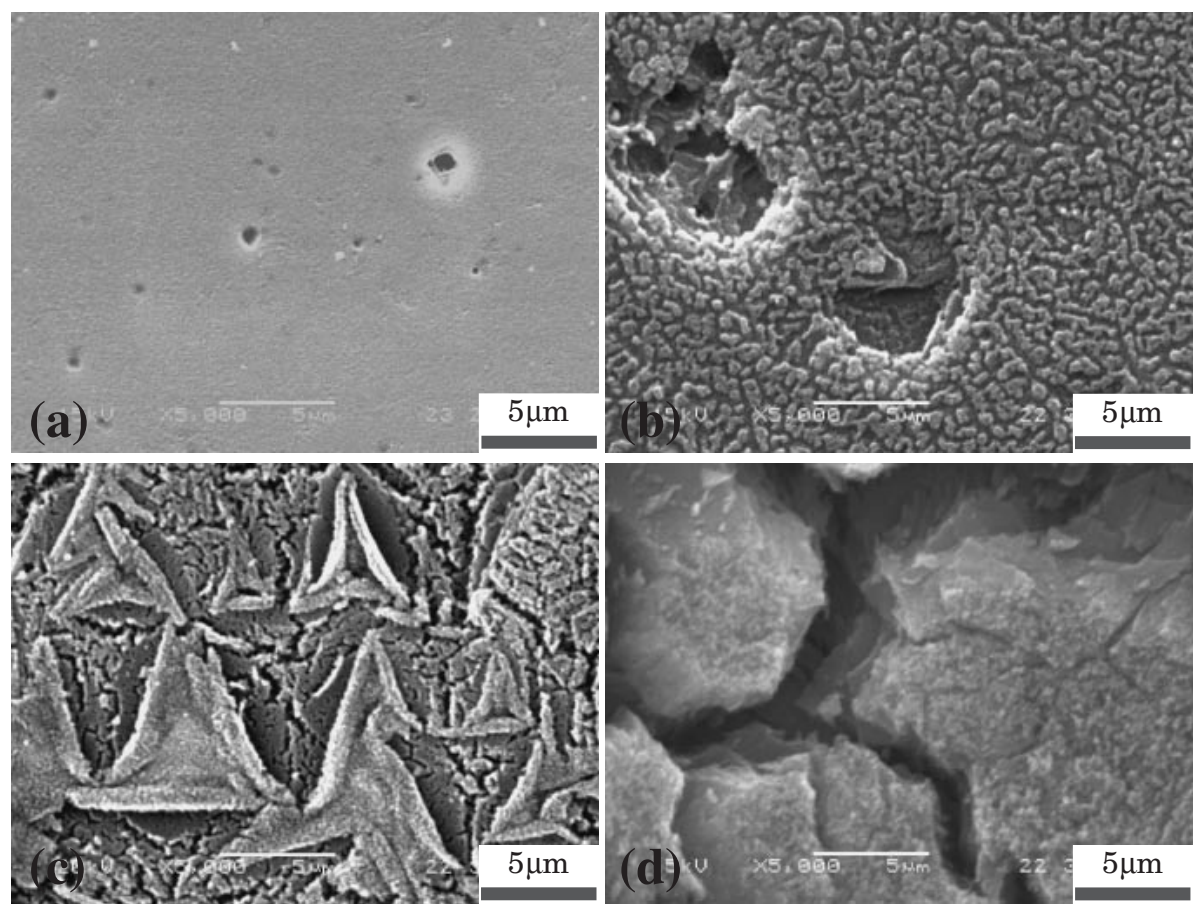

Fig. 14 Effect of temperature on the surface morphology after gasification under 30 vol\% $\mathrm{CO}_{2}$. (a) $1273 \mathrm{~K}$, reaction degree $0.2 \%$, (b) $1373 \mathrm{~K}$, reaction degree $1.5 \%$, (c) $1473 \mathrm{~K}$, reaction degree $5.5 \%$, (d) $1573 \mathrm{~K}$, reaction degree $21 \%$.

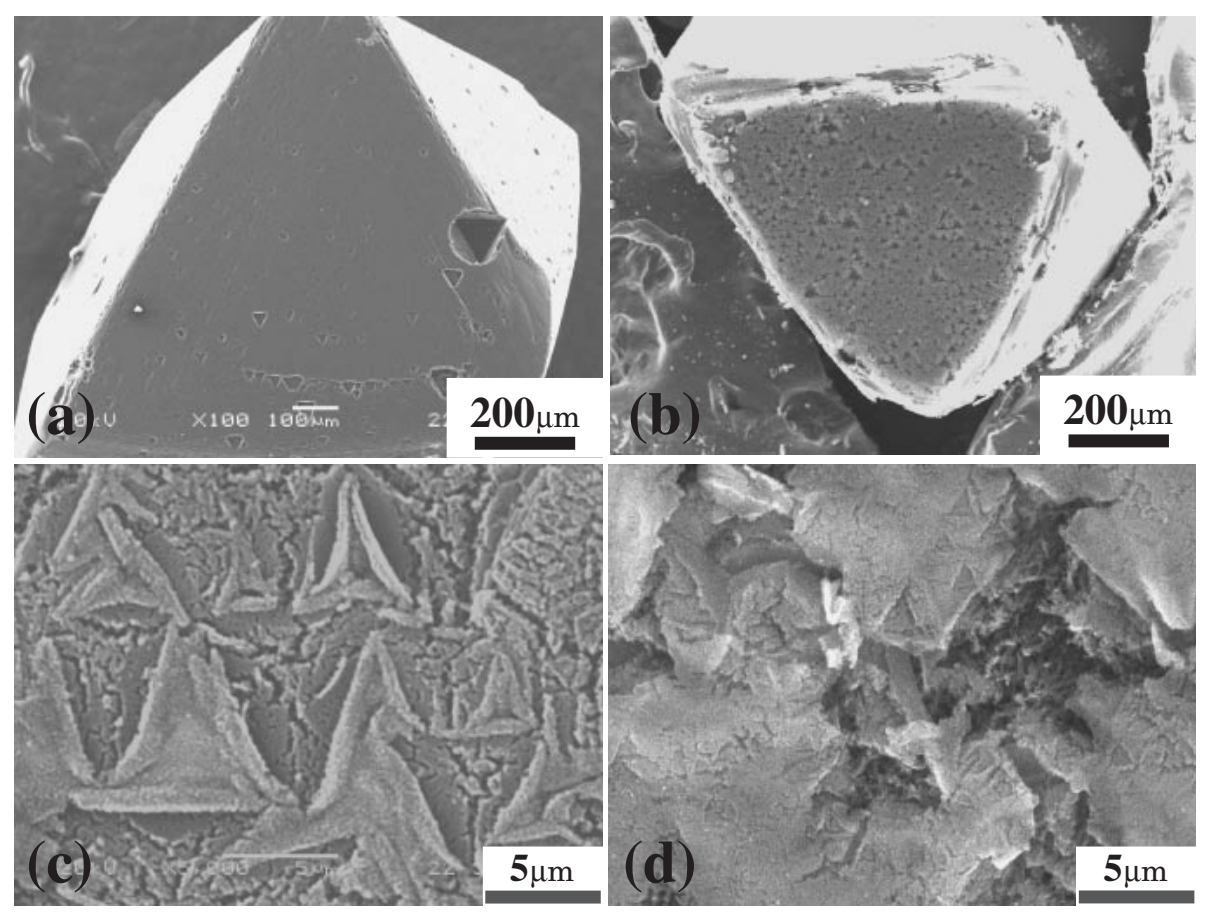

Fig. 15 Effect of reaction time on the surface morphology after gasification under $30 \mathrm{vol} \% \mathrm{CO}_{2}$ at $1473 \mathrm{~K}$. (a)(c) $30 \mathrm{~min}$, reaction degree $5.5 \%$, (b)(d) $90 \mathrm{~min}$, reaction degree $16.4 \%$.

\subsection{Simultaneous reaction between diamond and graph- ite}

It was strange that the graphite structure was formed on the surface of the diamond during gasification, because generally, the reactivity of graphite is higher than that of diamond. Even if graphite formed during the diamond gasification, the formed graphite should be consumed earlier than the diamond structure. However, as mentioned in previous results, ${ }^{8)}$ a graphite structure did exist on the surface of the diamond. Therefore, this structure should be different from that of ordinary graphite. In the present study, both reactivities were examined through the simultaneous reaction between graphite and diamond.

High purity graphite (ash $<20 \mathrm{ppm}$ ) was cut into almost the same size as the diamond sample. The gasification degree was measured together with the diamond sample (Exp-6: 


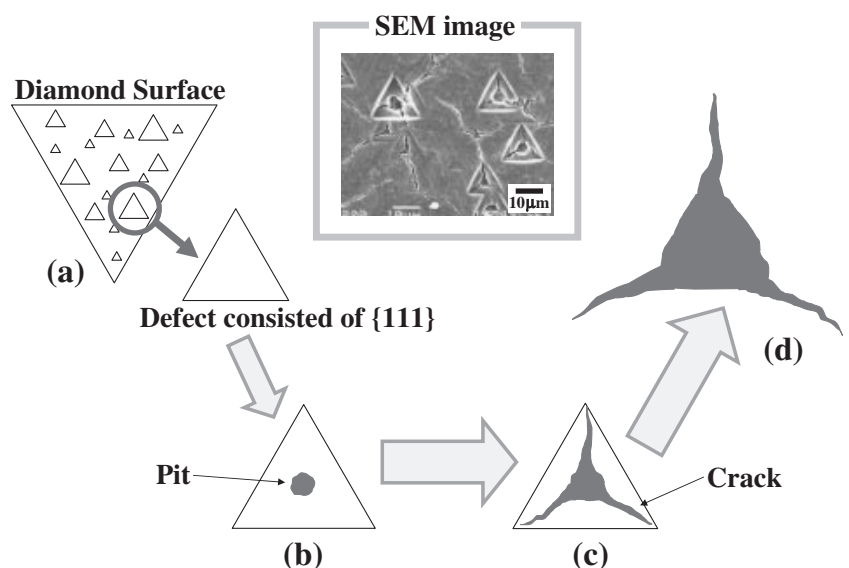

Fig. 16 Illustration of gasification process on the surface of diamond.

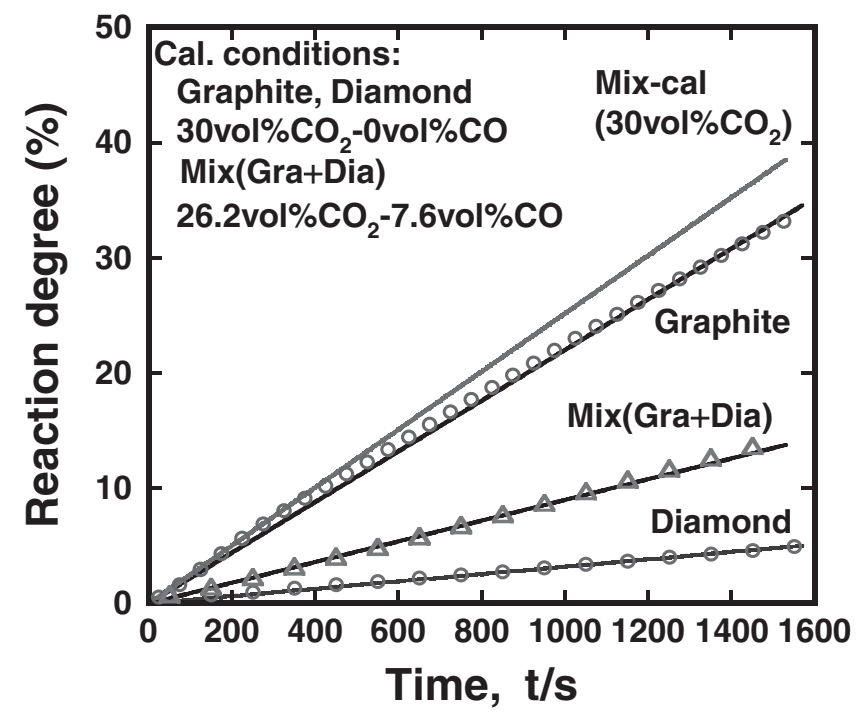

Fig. 18 Result of simultaneous reaction on diamond and graphite in comparison with the calculation results considering the effect of produced gas $(\mathrm{CO})$ to the neighbor sample.
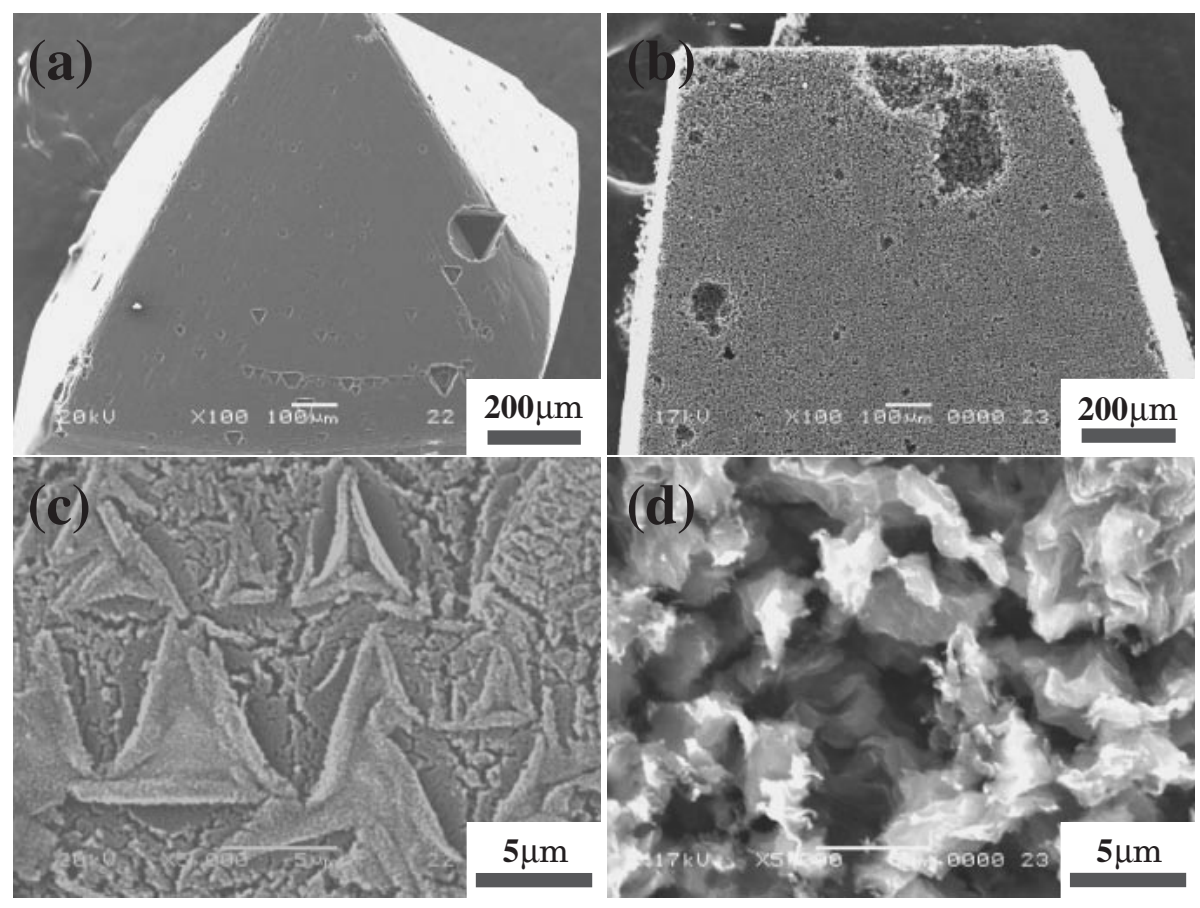

Fig. 17 Surface morphology after gasification under $30 \mathrm{vol} \% \mathrm{CO}_{2}$ at $1473 \mathrm{~K}$. (a),(c) diamond, reaction degree 5.5\%, (b),(d) graphite, reaction degree $34 \%$.

30 vol\% $\left.\mathrm{CO}_{2}, 1473 \mathrm{~K}, 1800 \mathrm{~s}\right)$. The two samples were then set in the Pt crucible ( $5 \mathrm{~mm} \phi, 2.5 \mathrm{~mm}$ in depth).

The surface morphology was observed by SEM and is shown in Fig. 17. In comparison with diamond, the gasification reaction in graphite proceeded throughout the surface. Some of the pits grew larger, ranging in size from $100 \mu \mathrm{m}$ to $200 \mu \mathrm{m}$. Overall, small pits $(1 \mu \mathrm{m}$ to $10 \mu \mathrm{m})$ existed over the whole surface.

Figure 18 shows the reaction curves for the diamond, the graphite and the simultaneous reaction between diamond and graphite $(\mathrm{Mix}(\mathrm{Gra}+\mathrm{Dia}))$. The lines for the graphite and diamond were calculated by using the equations from (16) to
(20). $F_{\mathrm{d}}$ for diamond is 0.116 and $F_{\mathrm{d}}$ for graphite is 0.8 , which were in excellent agreement with the observations in the single reaction.

When the simultaneous reaction was carried out, the apparent reaction degrees decreased in the both samples. However, the proportions of the decrease were different between two samples (Diamond: $-1.9 \%$, Graphite: $-3 \%$, Table 3). These results would be caused by the increase of CO gas content around the sample in the crucible, because of relatively large amount of reaction.

The preliminary calculation (Mix-cal) for the simultaneous reaction was carried out using the summation of the single 
Table 3 Simultaneous gasification degree in comparison with the single reaction.

\begin{tabular}{lccc}
\hline & $\begin{array}{l}\text { Single } \\
\text { reaction: } A\end{array}$ & $\begin{array}{l}\text { Simultaneous } \\
\text { reaction: } B\end{array}$ & $D=B-A$ \\
\hline Diamond & $5.6 \%$ & $3.7 \%$ & $-1.9 \%$ \\
\hline Graphite & $36.0 \%$ & $33.0 \%$ & $-3 \%$ \\
\hline
\end{tabular}

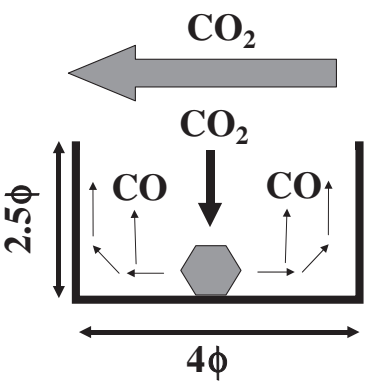

(a) Single sample

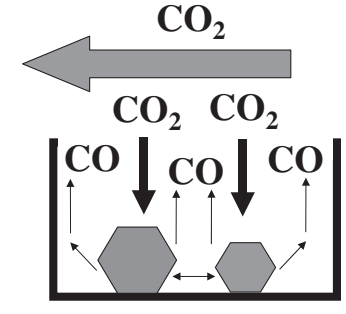

(b) Two samples
Fig. 19 Illustration of gas flow around sample(s) between the single sample and the two samples.

sample reaction, in which the gas composition was the same as the bulk gas $\left(30 \mathrm{vol} \% \mathrm{CO}_{2}\right)$. The calculated result fairly exceeded the observation. Then, the final calculation was performed on the base of the assumption that the $\mathrm{CO}$ gas produced affected the neighboring sample. The calculation result is shown with line in Fig. 18 as a Mix(Gra and Dia). The excellent agreement was obtained. In the case of this calculation, the $\mathrm{CO}$ gas concentration was $7.6 \mathrm{vol} \%$, and the decrease of $\mathrm{CO}_{2}$ equaled to a half of $\mathrm{CO}$ increase $\left(26.2 \mathrm{vol} \% \mathrm{CO}_{2}\right)$. This result is caused by the gas flow in the crucible (Fig. 19). The flow rate was $500 \mathrm{Ncc} / \mathrm{min}$, which was confirmed that there is little effect of mass transport on the rate of reaction. However, this situation might valid in the case of single sample in the crucible as shown in Fig. 19(a). When there are two samples in the crucible (Fig. 19(b)), the produced gas will affect on the neighboring sample. As a result, the effective reaction gas on the gasification reaction in the present experiment was changed to $26.2 \mathrm{vol} \% \mathrm{CO}_{2}-7.6 \mathrm{vol} \% \mathrm{CO}$.

The explanation of the value of Fd will be difficult. The value includes the effects of an effective surface area changing from the content and composition of ash in the coke. On the other hand, the diamond is a dense material and the number of reaction site is very low corresponding to graphite material. From these complex effects, the values of Fd ( 0.116 for diamond, and 0.8 for graphite) will be decided. However, the quantitative discussion is difficult at present. Further progress on this field will make possible to explain those meaning of parameters.

The rate of gasification of the diamond was quite low in comparison with the graphite and about $1 / 7$ to the graphite. Nevertheless, a graphite structure formed on the surface of diamond during gasification, the rate of gasification was low, which meant that the graphite like structure is different from the actual graphite.

\section{Conclusions}

Using TG-DTA, the gasification of diamond was investigated. Kinetic analysis was performed on the basis of a Langmuir-Hinshelwood type rate equation, which was modified from the previous study for coke gasification. SEM observation of the diamond surface was carried out in order to clarify the change in surface morphology associated with varying experimental conditions. Moreover, the simultaneous gasification of diamond and graphite was carried out in order to clarify the difference in reactivity between the ordinary graphite and the one formed on the diamond during gasification. The following results were obtained.

(1) The L-H type equation can be used to express the gasification of diamond and graphite.

$$
k^{\prime}=\frac{F_{\mathrm{d}} k_{1, \mathrm{~d}} P_{\mathrm{CO}_{2}}}{1+k_{2, \mathrm{~d}} P_{\mathrm{CO}}+k_{3, \mathrm{~d}} P_{\mathrm{CO}_{2}}}
$$

The parameters are $F d=0.116$ for diamond and $F d=0.8$ for graphite. The rate constants are as follows:

$$
\begin{aligned}
& k_{1, \mathrm{~d}}=\exp (9.49-24200 / T), \\
& k_{2, \mathrm{~d}}=\exp (-15.8+27700 / T), \\
& k_{3, \mathrm{~d}}=\exp (-5.53+5680 / T) .
\end{aligned}
$$

It was found that the activation energies were the same as for graphite in coke, but the frequency factor was lower than that of graphite.

(2) One of the main reaction site was the center of a equilateral triangle consisting of $\{111\}$, which became a pit through gasification. The pit and three cracks were enlarged and became deep in accordance with gasification. The surface morphology was changed by varying the experimental conditions such as the temperature and the oxygen potential in the gas.

(3) From the simultaneous reaction of diamond and graphite, it was found that the reactivity of the graphite that formed on the diamond surface was different from that of ordinary graphite. Its structure would be close to that of graphite, however, its chemical properties would be different from ordinary graphite.

\section{REFERENCES}

1) P. L. Walker, Jr., F. Rusinko, Jr. and L. G. Austin: Advances in Catalysis, XI (1959) 133.

2) P. C. Koening, R. G. Squires and N. M. Laurendeau: Fuel 65 (1986) 412-416.

3) T. W. Kwon, S. D. Kim and D. P. C. Fung: Fuel 67 (1988) 530-535.

4) Y. Kashiwaya and K. Ishii: Tetsu-to-Hagane 76 (1990) 1254-1259.

5) Y. Kashiwaya and K. Ishii: ISIJ int. 31 (1991) 440-448.

6) Y. Kashiwaya and K. Ishii: Tetsu-to-Hagane 79 (1993) 1305-1310.

7) Y. Kashiwaya and K. Ishii: Tetsu-to-Hagane 79 (1993) 1311-1316.

8) Y. Kashiwaya, M. Iwasa and K. Ishii: Mater. Trans. 49 (2008) 15791588 . 